2017-01-27

\title{
Comparative Research on the Attitudinal Competence for Early Childhood Education and Care in Europe
}

\section{Campbell-Barr, Verity}

http://hdl.handle.net/10026.1/8329

\subsection{5/9781473982307}

Sage Research Methods

All content in PEARL is protected by copyright law. Author manuscripts are made available in accordance with publisher policies. Please cite only the published version using the details provided on the item record or document. In the absence of an open licence (e.g. Creative Commons), permissions for further reuse of content should be sought from the publisher or author. 


\section{Comparative Research on the Attitudinal}

\section{Competence for Early Childhood Education}

\section{and Care in Europe}

\section{Verity Campbell-Barr}

University of Debrecen, Hungary; Plymouth University, UK. Email: verity.campbell-

barr@plymouth.ac.uk

\section{Jan Georgeson}

Plymouth University, UK

Accepted 1 April 2016

Published 27 January 2017 


\section{Contributor Biographies}

Verity Campbell-Barr is a lecturer in early childhood studies at Plymouth University, undertaking a Marie Curie European Research Fellowship (funded by the European Commission) in the Department of Child Education at the Faculty of Child and Adult Education, University of Debrecen, Hungary. Her research interests center on the quality of early childhood services, with her fellowship focusing on the knowledge, skills, and attitudes required of the early childhood education and care workforce. She has a background in researching the provision of early childhood services and policy developments in early childhood education and care.

Jan Georgeson is a research fellow at Plymouth University, currently investigating professional development for early years practitioners, especially in the context of multiagency working and working with very young children. She has a background in teaching young children with special educational needs, particularly speech, language, and communication difficulties. Jan carried out research at Birmingham University from 1995 onward, completing an EdD in Educational Disadvantage and Special Educational Needs in 2006. Since then she has worked on a range of research projects on disability, special educational needs, and provision in the early years.

\section{Published Articles}

Campbell-Barr, V., Georgeson, J., \& Nagy Varga, A. (2015). Developing professional early childhood educators in England and Hungary: Where has all the love gone? European Education, 47, 311-330.

Georgeson, J., Campbell-Barr, V., Bakosi, É., Nemes, M., Pálfi, S., \& Sorzio, P. (2015). Can we have an international approach to child-centered early childhood practice? Early Child Development and Care, 185, 1862-1879. 


\begin{abstract}
The case study presented considers the challenges and rewards of undertaking cross-cultural comparative research. Through discussing a mixed method project, there is an exploration of how it is important not to assume shared understandings of both research approaches and subject-specific terminology. Research approaches vary across countries and what may seem straight forward for one partner in a cross-cultural project may not be for another and that time is needed to ensure a shared understanding. In analyzing the data, the issue of translation highlights that while we believe we are talking about the same terms, closer analysis of how terms are being used demonstrates the importance of asking questions of apparent similarities. Translation can often be a "best fit" where an exact translation is not possible, resulting in the true meaning becoming masked and hidden. Equally, differences identified can help to ask questions of taken for grant assumptions in one context, demonstrating the importance of understanding the cultural context for disentangling the data.
\end{abstract}

\title{
Learning Outcomes
}

By the end of this case, students should be able to

- Summarize the purpose, challenges, and advantages of conducting cross-cultural research

- Construct an understanding of how to conduct cross-cultural research

- Critically assess the issue of translation in cross-cultural research 


\section{Case Study}

\section{Project Overview and Context}

The aim of the research presented in this case study was to consider the attitudinal competences required in the context of early childhood education and the role of higher education (HE) in developing the identified attitudes. The research was motivated by the European Key Competences for Lifelong Learning that provide a European-level reference tool for education providers, including HE institutions, to focus national- and European-level efforts to support students toward personal fulfillment, social inclusion, active citizenship, and employability in a knowledge-based society. The European Lifelong Learning Programme defines competences as a combination of knowledge, skills and attitudes appropriate to the context. (European Commission, 2007)

There are eight essential key competences (communication in the mother tongue, communication in foreign languages, mathematical competence and basic competence in science, digital competence, learning to learn, social and civic competence, sense of initiative and entrepreneurship, and cultural awareness and expression), but we were particularly interested in the idea of attitudes within the statement of lifelong learning for the context of early childhood education and care. Coming from the field of early childhood education and care we are aware how often people refer to working with young children as requiring a set of innate dispositions and this raised questions for us about the role of qualifications in developing these dispositions. In the United Kingdom, recent developments to upskill those who work in early childhood education and care settings have increased the focus on degree qualified staff and this prompted 
us to consider the role of a degree in developing the attitudes needed for working with young children — can we teach attitudes? Given that Key Competences exist as a European-level document, we also wondered whether there could be commonality in the attitudes needed for the context of early childhood education and care across Europe. The European focus was also motivated by our own observations when visiting early childhood education and care settings in different countries and noticing that, while there are many similarities, there are also differences that we wanted to understand better. Some of the differences are overt, such as the different names given to those who work in early childhood education and care settings across Europe, but others are more subtle and it was these that we were particularly interested in exploring. Our research therefore looked to consider what are the key attitudinal competences that HE lecturers and students would advocate for early childhood education and whether there are commonalities across European countries.

We appreciated that it would be challenging to consider all European countries, partly as our resources (notably research funding) were limited, but also because we needed to be able to manage the size and scale of the project. We identified European partners from our own networks, looking to get representation from countries with different experiences and histories in terms of early childhood education and care provision. We found that initially the people we approached were very enthusiastic, but as the project developed not all of them engaged in the data collection, probably as a result of other commitments. Four HE partners were involved in the project, two from the United Kingdom, one in Italy, and one in Hungary. This is best described as a convenience sample and, because of this, we were conscious that our findings could not be considered representative; instead, they offered a starting point for better 
understanding the concept of attitudes in the context of early childhood education and care in Europe.

\section{Comparative Education Research}

Comparative research in education has a long history (Alexander, 2000), with different intentions behind the comparison depending on the purpose of the stakeholders involved. Comparative research can be about considering what we can learn from looking at another country's education system and making comparisons on educational performance, such as academic attainment. The Programme for International Student Assessment (PISA) study conducted by the Organisation for Economic Co-operation and Development (OECD) that considers the knowledge and skills of 15-year olds in different countries is an example of how comparative research can be used to compile global league tables to compare educational performance between countries. While news reports might focus on league tables ranking countries on the performance of their 15 -year olds in the test, there will also be attempts to look for explanations of differences between scores, such as how socio-economic status might influence children's performance as well as what is it that high-achieving countries do in their pedagogical practice that might have led to high scores—what "best" practice might be adopted by other countries? In looking at best practice, attention is given to the detail of the education system to see what can be learnt. Importantly, this particular form of comparative research increasingly takes into account a country's cultural context, appreciating that learning from best practice is not as simple as transferring aspects of one education system into another county. Culture and history become central to explaining embedded education ideals and values and the comparative process enables a richer understanding of what these ideals and values are. 
Comparative education research can therefore vary not only in its size and scope but also in its conduct. Native researchers might collect data on their home context and then share this with international partners; alternatively, the research might adopt a tourist approach, whereby a research team visits another country to collect data. In the latter case, questions arise over how well the researchers understand the culture of the context in which they are collecting data; however, it is possible that this form of comparative research enables researchers to bring to the surface taken for granted assumptions and to ask questions about practice in both of their own and of their host country (Tobin, Hsueh, \& Karasawa, 2009). Both of these models assume that primary data are being collected, but there are a number of international data sets that can be accessed for research purposes. We would argue that even in looking at these data sets there is a need to appreciate the context of a country to foster understandings of the data.

\section{Research Design and Practicalities}

We designed our comparative research to be undertaken by native researchers, collecting data using the same research instruments so that the findings could then be shared and we could ask each other questions about the findings. We adopted a sequential mixed method design, first conducting separate staff and student focus groups to identify the attitudes that they felt were important for early childhood education and care in their home country, and then using findings from the focus groups to inform an online student questionnaire. The research design seemed self-apparent to us; we assumed that our partners would have a shared understanding of how to conduct such research and its associated requirements, including meeting ethical standards. However, we came to appreciate that, while we might be comfortable with particular research terms and approaches, this did not mean that our partners had the same level of comfort. First, 
there was the challenge of developing a shared ethics protocol that would guide those undertaking the research. In the UK context, we are well used to considering the ethics of undertaking a piece of research, particularly where the research participants were our colleagues and students, and our university has a well-established Education Ethics Committee. However, one of our European partners had no ethics committee; while they aimed to be ethical in their research approach, they had never had to consider and document the ethical issues of a piece of research. Although our partner was keen to start on their data collection, we had to ask them to wait while we developed an ethics protocol. We developed an ethics check list and short video that our partners could follow to ensure consistency across the project in explaining the ethical considerations of the research to the participants, as well as developing an information sheet for the research participants that was translated into the native language. However, we were aware that already the cultural context was shaping the research. The ethical protocols had been developed in line with our UK values; while these clearly overlapped with our partners', it prompted us to consider what might have happened had one of our partners been from outside of Europe - might there have been fewer overlaps? Furthermore, in our partner's context where information sheets had not previously been provided, their introduction might seem strange to participants; taking part in this research would have a different look and feel to other research conducted in this context.

The second challenge we faced concerned understanding how to conduct a focus group. We had developed a set of questions for the focus groups using a semi-structured style, with several broad questions designed to stimulate discussion. We felt that using a semi-structured approach would enable those conducting the focus groups to ask follow-up questions that were appropriate for their own context. However, in the focus group with lecturers, one of our partners 
asked each question in turn with no follow-up questions because they had not appreciated that the semi-structured approach allowed them some freedom in their questioning_-"semistructured" was not a term that translated easily. The data were therefore limited and, although we were able to ask them to develop more questions for the focus group with the students, it made us appreciate the need in comparative research to explain all research terms carefully.

\section{Lost in Translation}

The focus group data from Italy and Hungary were translated into English for the purpose of the analysis so that all the data could be considered using one coding framework. However, we soon discovered the challenges of shared understanding in translating the data that we had collected. In some instances, the issues of translation related to specific terms, but in others the notion of actually achieving a shared understanding became an important feature of the research. For example, considering the issue of translating particular terms, in Hungary those who work in early education (kindergarten) settings are óvodapedagógus. Often this is translated as "kindergarten teacher," but our Hungarian partners explained to us that "teacher" was not the right word as in early years education in Hungary they do not see the pedagogue as having a role in "teaching" children; teaching for them was something that takes place in schools. Examples like this led us to appreciate that we needed to ask questions about each term that we were using to see whether we had shared understandings.

Within research, language can often be taken at face value, whereby there is an assumption that there is a shared understanding between participant, researcher, and audience. Yet when asked to translate terms, a difference between formal and dynamic translation becomes apparent (Alexander, 2000); the former considers the literal translation, but the latter seeks a 
better understanding of the translation. As a first stage to help with understanding the translation of tricky words, the native speakers included notes on the transcripts to help explain terms. However, even where translation appeared easy, we discovered that this was rarely the case.

One particular term that is often used in relation to early childhood education and care is "child-centered." It was a term that came up again and again in the focus groups across the countries and from both staff and students. However, in scrutinizing our data, we came to appreciate that there were different interpretations of child-centered practice shaped by the cultural context of the country. Drawing on previous research (Chung \& Walsh, 2000), we were able to explore three strands of child-centered practice: a perception of the child at the center of their world, a developmentalist view of the child at the center of their learning, and a democratic view that a child should direct their own learning. Within our analysis we were able to unpick the way in which the cultural context, particularly policy, was shaping understandings of the attitudes to children's autonomy that are needed to work with young children (Georgeson et al., $\underline{2015)}$.

Translation of terms also highlighted ways in which different cultures talked about early years of education. From the focus groups we identified a range of terms that students and lecturers used to describe the attitudes needed to work with young children. We used these terms as the basis for an online questionnaire for students (conducted in the native language) where they were asked to rate on a scale of 1-10 how important they thought each of the attitudes was. Through comparing the average score given in each of the countries, we found that the questionnaire helped to identify possible areas of difference between countries (Campbell-Barr, Georgeson, \& Nagy Varga, 2015). However, the differences alone did not tell us very much; we needed both to revisit the qualitative data and to discuss why we thought there were differences 
in the data. In some instances, translation was hiding the meaning. For example, students in the United Kingdom talked of "compassion" as a necessary attitude for working with young children, but it was hard to find a way to translate "compassion" into Hungarian, particularly in the context of early childhood education and care, as it was not a term that would be used in this context. This example, and others, highlighted how the language used to talk about early childhood education and care was shaped by the cultural context; where words seemed strange or unusual to us as English speakers, we began to appreciate that there are culturally prescribed ways to discuss early childhood education and care. One example for us was the use of "loving" as a necessary attitude for working with young children in Hungary. In the UK context, the use of love seemed strange, while our Hungarian partners never stopped to question the importance of love. This difference highlights how the comparative element of the research prompted us to ask questions about what was taken for granted in the different contexts; one of the challenges was, however, to try and understand what had shaped the differences. Was it to do with the limitations of the language available or something within the cultural context? To attribute the difference to the cultural context alone was not however sufficient; we also needed to understand the specificities of the cultural context. For example, we have explored how in the UK context a strong child protection discourse is shaping understandings of the attitudes needed for working with young children (Campbell-Barr et al., 2015) — and this means that "love" is too strong a word in this context.

In developing an understanding of the cultural context, it is also important to consider the interplay between different aspects of the data. The questionnaire on its own demonstrated a difference, but we had to return to the qualitative data to try and understand the differences. We also needed to look at the interplay between the differences that we were noticing. Exploring one 
difference in isolation was not sufficient for us to develop an understanding of the cultural context. For example, another difference that we noted was that in the UK data students identified with a need to be politically aware, but this was not so evident in Italy or Hungary. In the United Kingdom, early childhood education and care has received a lot of political attention in recent years and this attention has not always been welcome, helping to explain why the average scores given to political awareness were higher in the United Kingdom than elsewhere. The influence of political intervention in the United Kingdom also helped us to understand why love was not a feature of early childhood education and care in the United Kingdom; policy has removed the reference to love in curriculum documents. In appreciating this difference, we developed a better understanding of the importance of the each country's political history in shaping attitudes to work in early childhood education and care (Caruso \& Sorzio, 2015; Nagy

Varga, Molnar, Palfi, \& Szerpi, 2015). The comparative element of the project therefore entailed not just comparing the data that we were collecting but also reading widely to help us to understand the differences.

\section{Lessons Learned}

What we have learnt from undertaking this piece of research is the true complexity of carrying out comparative education research. We have had to become experts in language and history to understand our findings. However, it has also made us appreciated that, just as our findings highlighted cultural differences in understanding attitudes for early childhood education and care, there are also cultural differences in understandings of research. Understanding what is a semi-structured focus group or developing an ethics protocol is certainly part of the cultural context for undertaking research in our country, but this is not necessarily true for all countries. 
We can appreciate now that more time should have been given at the outset of the project to discuss the research approach and we should not have assumed that all partners were comfortable with the research instruments. Ideally we would also share examples of data earlier so that partners could develop a shared understanding of the kind of data that could emerge and how the research instruments should be used.

Using native speakers in the research process has been invaluable. The translation process is not as simple as just translating the individual words, it also involves a process of translating the translation in order to explain why some words are used and not others. Being able to ask questions of the translators contributed considerably to developing our understanding of the data, but has also given us an appreciation of the challenges of undertaking comparative educational research. There is a lot to be learnt from sharing ideas, but it is important to appreciate the complexities of translation and the challenges of finding translations that do not lose subtleties of the original meaning.

\section{Conclusion}

The research has been helpful in contributing to our understandings of early childhood education and care in our home context and exploring the ways in which we talk about the attitudes needed for working with young children. What our participants described as normal in their own contexts has prompted us to question that norm and to seek to understand it better while also posing questions about the other contexts. In addition, the research has opened up alternative ways for understanding the attitudes needed for working with young children-loving or compassionate or both? Undertaking cross-cultural research is challenging; you cannot be completely sure what the data set from a research partner will look like until it arrives, but this is 
where having good relationships with your research partners can really help. You need to be able to ask questions of each other about the format of the data set and details about how it was collected, but you will also need to build in plenty of opportunities for discussion to refine understanding.

\section{Exercises and Discussion Questions}

1. We have highlighted the importance of translation in our research and we believe that it is important to use experienced translators in making sense of the translations. Electronic translators cannot identify the complexities of a translation and may not always be accurate. Write a question for a focus group on a subject of your choice. Place the question into an online translation program and translate it into five different languages and then back to your native language - is the question the same? Are there any words that could be difficult to translate, where your meaning might be different to the translated one?

2. Do you think it is necessary to translate the data into one language so that it can be analyzed in one data set?

3. The research presented focused on Europe; how do you think it might have varied if a partner from South America (for example) had been included?

4. Do you think one research partner should impose their ethical requirements onto other partners? Would the imposition alter the nature of the data being collected?

\section{Further Reading}


Georgeson, J., Campbell-Barr, V., Bakosi, É., Nemes, M., Pálfi, S., \& Sorzio, P. (2015). Can we have an international approach to child-centred early childhood practice? Early Child Development and Care, 185, 1862-1879.

Tobin, J., Hsueh, Y., \& Karasawa, M. (2009). Preschool in three cultures revisited: China, Japan, and the United States. Chicago, IL: University of Chicago Press.

\section{Web Resources}

https://ececworkforce.wordpress.com/

\section{References}

Alexander, R. J. (2000). Culture and pedagogy: International comparisons in primary education. Malden, MA: Blackwell.

Campbell-Barr, V., Georgeson, J., \& Nagy Varga, A. (2015). Developing professional early childhood educators in England and Hungary: Where has all the love gone? European Education, 47, 311-330.

Caruso, F., \& Sorzio, P. (2015). The complex construction of professionalism in ECEC service in Italy. In V. Campbell-Barr \& J. Georgeson (Eds.), International perspectives on early years workforce development (pp. 40-54). Northwich, UK: Critical Publishing.

Chung, S., \& Walsh, D. J. (2000). Unpacking child-centredness: A history of meanings. Journal of Curriculum Studies, 32, 215-234. 
European Commission. (2007). Key competences for lifelong learning: European reference framework. Brussels, Belgium: Author.

Georgeson, J., Campbell-Barr, V., Bakosi, É., Nemes, M., Pálfi, S., \& Sorzio, P. (2015). Can we have an international approach to child-centred early childhood practice? Early Child Development and Care, 185, 1862-1879.

Nagy Varga, A., Molnar, B., Palfi, S., \& Szerpi, S. (2015). Hungarian perspectives on the early years workforce development. In V. Campbell-Barr \& J. Georgeson (Eds.), International perspectives on early years workforce development (pp. 105-117). Northwich, UK: Critical Publishing.

Tobin, J., Hsueh, Y., \& Karasawa, M. (2009). Preschool in three cultures revisited: China, Japan, and the United States. Chicago, IL: University of Chicago Press. 